\title{
Primary Intraosseous Carcinoma Arising in a Mandibular Keratocystic Odontogenic Tumor: A Case Report
}

\author{
Vikram Sharma ${ }^{1}$, Harshdeep Dhaliwal ${ }^{2}$, Satyapal Yadav ${ }^{3}$
}

\begin{abstract}
Primary intraosseous carcinoma (PIOC) is a rare squamous cell carcinoma (SCC) arising within the jaw, which has no initial connection with the oral mucosa, overlying skin, antral or nasal mucosa. Primary intraosseous carcinoma is also designated as odontogenic carcinoma because it is considered to develop from the epithelium involved in odontogenesis. It is considered a rare lesion, but may not be as rare as commonly believed. It may arise de novo or as a consequence of malignant transformation of a benign cyst or tumor. It is locally aggressive with a poor prognosis. A case of primary intraosseous SCC of the mandible, with evidence of origin in an odontogenic cyst, is presented.

Keywords: Keratocystic odontogenic tumor, Mandible, Primary intraosseous carcinoma, Primary intraosseous squamous cell carcinoma.

Journal of Mahatma Gandhi University of Medical Sciences \& Technology (2020): 10.5005/jp-journals-10057-0126
\end{abstract}

\section{INTRODUCTION}

Primary intraosseous carcinoma (PIOC) is defined as "A squamous cell carcinoma arising within the jaw, having no initial connection with the oral mucosa and presumably developing from residues of the odontogenic epithelium" (according to WHO). WHO has also subcategorized it into three different types: (i) Primary intraosseous squamous cell carcinoma (PIOSCC) solid type (de novo); (ii) PIOSCC originating from keratocystic odontogenic tumors (KCOT), and (iii) PIOSCC originating from odontogenic cysts. ${ }^{1}$ The etiology of PIOC is not clear; however, the most common factor may be a reactive inflammatory stimulus with or without a predisposing genetic cofactor. Since squamous cell carcinomas (SCCs) may appear within the bone from other sources, the diagnosis of PIOC is by exclusion. ${ }^{2}$

This report describes an extremely rare case of a PIOC derived from a KCOT in a 41-year-old man.

\section{Case Description}

A 41-year-old male patient reported swelling on the left side of the face for the last 6 months. He was operated on elsewhere 1 year ago for a lesion that was histopathologically confirmed as KCOT. The patient had no contributing medical history. A general physical examination of the patient did not reveal any significant findings. All vital signs were in the normal range. He had a habit of tobacco chewing for the last 10 years thrice or four times daily which he had stopped after his first jaw surgery. There was a gross facial asymmetry with diffuse swelling involving the middle and lower third of the left side of the face extending from the ala-tragus line to approximately $2 \mathrm{~cm}$ beyond the inferior border of the mandible (Fig. 1). The swelling extended anteriorly to the symphysis and posteriorly to the posterior border of the ramus of the mandible. On palpation, the swelling was tender and firm in consistency. The jaw was deviated to the left side on opening and closing the mouth. The bilateral submandibular lymph nodes were palpable, tender, firm in consistency, and not fixed. Intraorally, vestibular obliteration was seen extending from the canine to the anterior border of the ramus, posteriorly (Fig. 2). There was no obvious relation between the mandibular mass and the overlying mucosa. On palpation intraorally, the findings of inspection were confirmed,
${ }^{1}$ Department of Oral and Maxillofacial Surgery, NIMS Dental College and Hospital, Shobha Nagar, Jaipur, Rajasthan, India

${ }^{2}$ Department of Oral Medicine and Radiology, NIMS Dental College and Hospital, Shobha Nagar, Jaipur, Rajasthan, India

${ }^{3}$ Department of Oral Medicine and Radiology, Mahatma Gandhi Dental College and Hospital, Jaipur, Rajasthan, India

Corresponding Author: Vikram Sharma, Department of Oral and Maxillofacial Surgery, NIMS Dental College and Hospital, Shobha Nagar, Jaipur, Rajasthan, India, Phone: +91 9636985159, e-mail: dr. vikram.omfs@gmail.com

How to cite this article: Sharma V, Dhaliwal H, Yadav S. Primary Intraosseous Carcinoma Arising in a Mandibular Keratocystic Odontogenic Tumor: A Case Report. J Mahatma Gandhi Univ Med Sci Tech 2020;5(3):96-99.

Source of support: Nil

Conflict of interest: None

while the swelling was tender and indurated with no cortical expansion. Entire maxillary dentition was present with angular

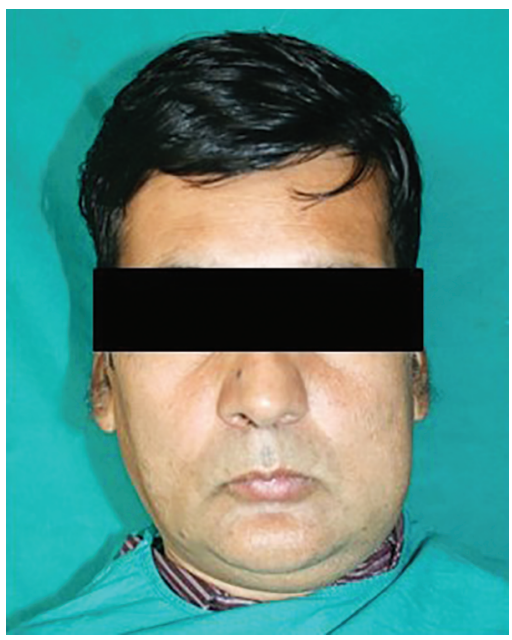

Fig. 1: Extraoral clinical photograph showing swelling on the left side of the face

(c) The Author(s). 2020 Open Access This article is distributed under the terms of the Creative Commons Attribution 4.0 International License (https:// creativecommons.org/licenses/by-nc/4.0/), which permits unrestricted use, distribution, and non-commercial reproduction in any medium, provided you give appropriate credit to the original author(s) and the source, provide a link to the Creative Commons license, and indicate if changes were made. The Creative Commons Public Domain Dedication waiver (http://creativecommons.org/publicdomain/zero/1.0/) applies to the data made available in this article, unless otherwise stated. 

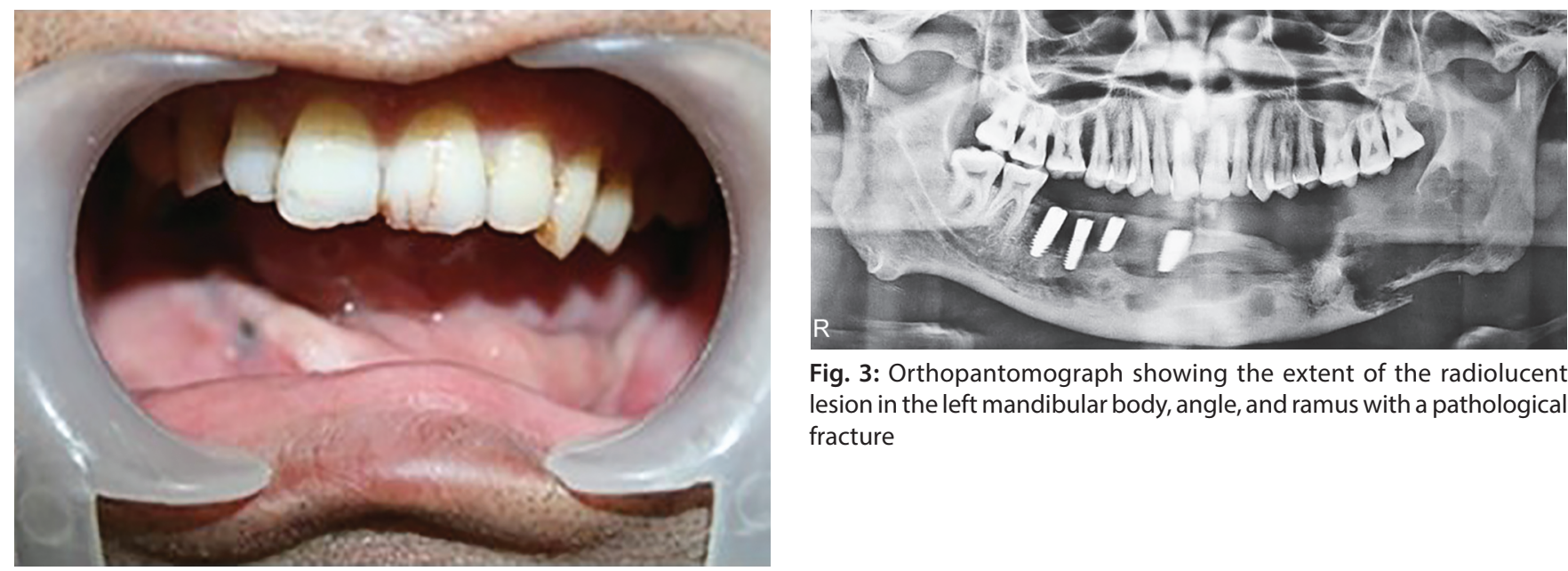

Fig. 3: Orthopantomograph showing the extent of the radiolucent lesion in the left mandibular body, angle, and ramus with a pathological fracture

Fig. 2: Intraoral picture showing vestibular obliteration

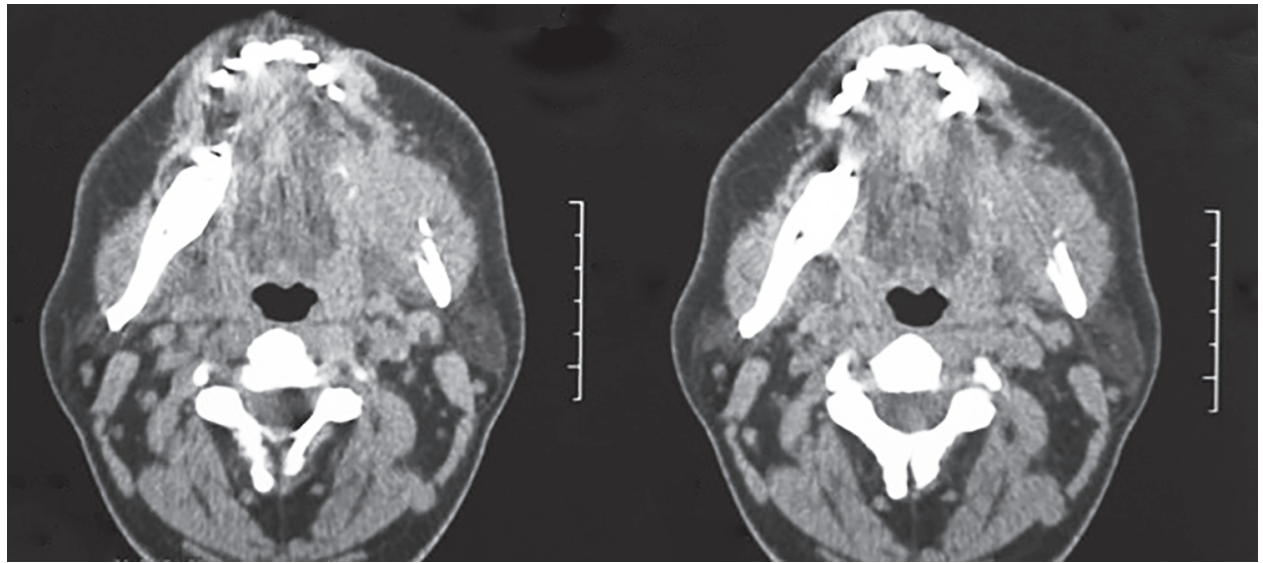

Fig. 4: Axial computed tomography section showing the destruction of the left mandibular body, angle, and ramus

bone loss. In the mandible, only teeth no 47,48 were present with implants in $41,44,45,46$. The history of extractions was when the patient got operated on for KCOT 1 year ago and he got implants done 2 months ago. Recurrent KCOT and ameloblastoma were considered in the differential diagnosis. Panoramic radiograph (OPG-orthopantomograph) revealed multilocular, an ill-defined large lesion with gross destruction of the left body and ramus of the mandible extending from the left lower canine to the mandibular ramus with a pathological fracture in the posterior left mandibular body (Fig. 3). A screening chest radiograph was made to rule out any primary lesion in the lungs; however, nothing abnormal was found. Routine blood investigations were carried out which were in the normal range.

Computed tomography (CT) scan was performed to know the extension of the lesion. It revealed a destructive lesion in the left half of the mandible in the body and angle region extending till the ramus sparing coronoid process and condyle. The lesion had destroyed both the cortices in this region. It showed a unicentric lesion with inside out growth and permeative type of destruction. The margins were indistinct with a wide zone of transition suggesting an intraosseous malignant neoplasm. The masseter and part of the pterygoid muscle were bulky suggesting infiltration. Pathological fracture of the posterior body was also evident (Fig. 4). Lymph nodes were not involved.
Initial clinical and radiographic diagnosis in our institution were suggestive of recurrent KCOT with pathological fracture of the body with a differential diagnosis of ameloblastoma and PIOC. Surgical resection was performed under general anesthesia and a reconstruction plate was placed (Figs 5 to 8). The histopathological examination of the specimen confirmed the diagnosis of poorly differentiated SCC in the wall of a KCOT. Follow-up of the patient showed satisfactory healing. The patient underwent radiotherapy after this in a cancer institute. To date, neither recurrence nor metastasis has occurred.

\section{Discussion}

Primary intraosseous carcinoma is a rare malignant lesion arising within the jawbones, and it was first described by Loos in 1913 as central epidermoid carcinoma of the jaws. It is known by a variety of names such as primary epithelial tumor of the jaw, intra-alveolar carcinoma of the jaw, primary intra-alveolar epidermoid carcinoma, and primary intra-alveolar SCC of the mandible. The term PIOC was coined by Pindborg et al. in 1971. ${ }^{3}$

The existence of a primary tumor in another site must be ruled out before PIOC can be diagnosed. The possibility that the lesion is a metastasis should be considered and discounted by obtaining a careful history and doing a thorough examination. Metastatic carcinoma of the mandible occurs mainly from the 


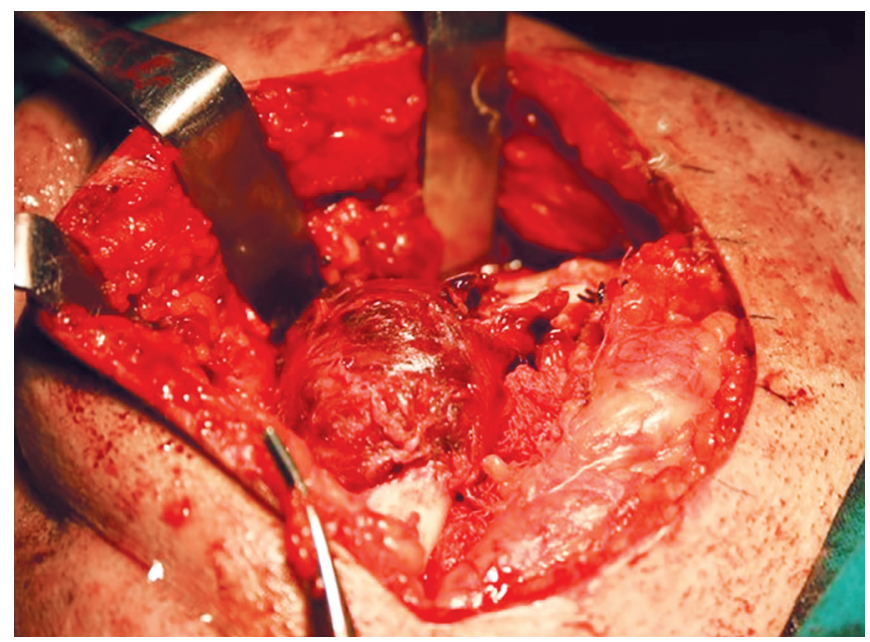

Fig. 5: Intraoperative picture showing the lesion

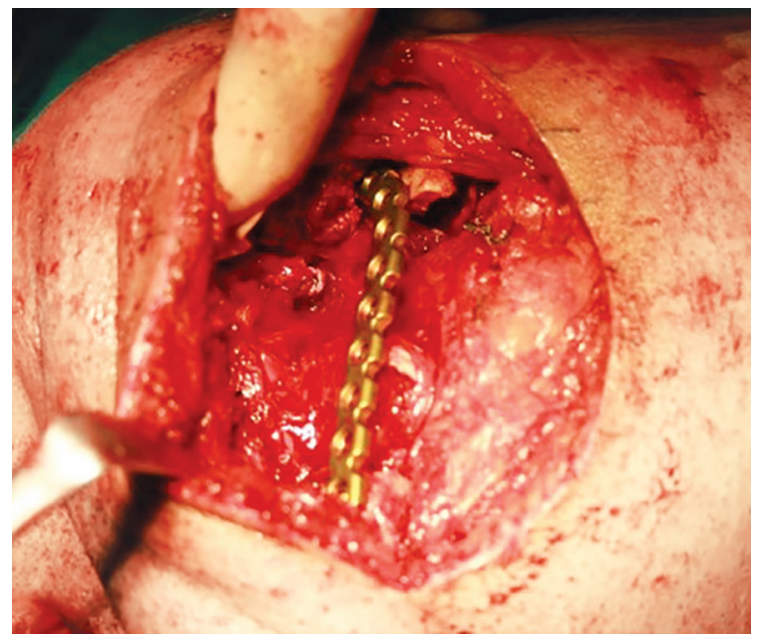

Fig. 7: Intraoperative picture showing the placement of reconstruction plate

breast, thyroid, kidney, and lung. To et al. reviewed the literature regarding metastasis to the jaw and concluded that investigation of the primary tumor should include chest radiography and that the patients must be followed for at least 6 months. ${ }^{4}$ We agree with this opinion and carried out thorough history, examination, chest radiograph, and follow-up with our patient.

Thomas et al. reviewed the pooled data of 35 cases of PIOSCCS (equivalent to the solid type) and showed the mean age of the patients to be 52.5 years ranging from 4 to 81 years. A male to female ratio of 2.5:1 was observed. ${ }^{5}$ Our patient was a man of 41 years.

Primary intraosseous squamous cell carcinoma is thought to originate from the odontogenic epithelium. ${ }^{6}$ This is supported by the location, in our case, being in the posterior part of the mandible, as are other benign odontogenic tumors or cysts.

The most common presenting symptoms of patients with PIOSCC were jaw swelling and pain in a study by Huang et al. ${ }^{7}$ Sensory disturbances, such as lip or facial paresthesia and numbness, occurred in $>70 \%$ of the mandibular cases. ${ }^{7}$ In our patient, swelling and tenderness were observed.

Radiographic examination is one of the most effective methods to detect PIOSCC. However, PIOSCCs show great variation in size and shape and in the appearance of their borders. Kaffe et al. ${ }^{8}$ have

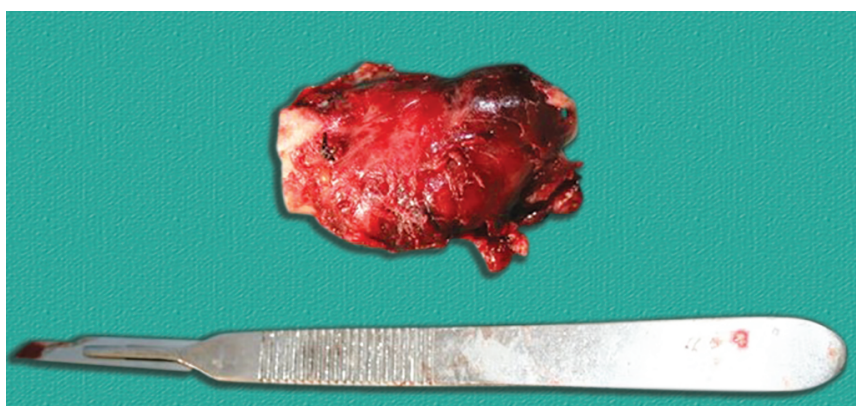

Fig. 6: Photograph showing resected tumor mass

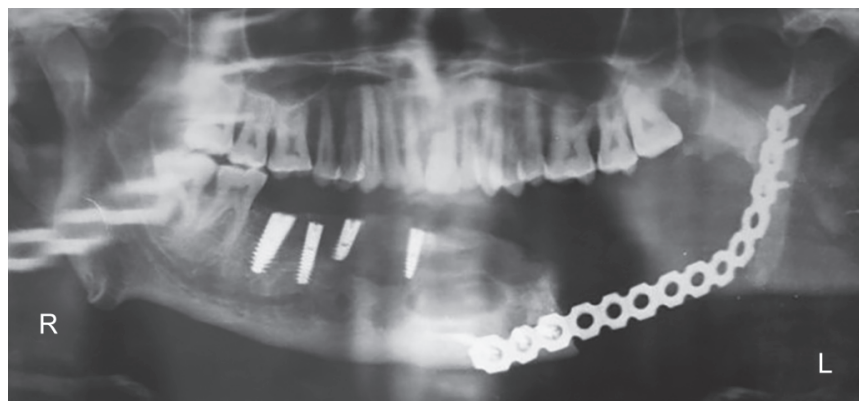

Fig. 8: Immediate postoperative orthopantomograph showing reconstruction plate

proposed that an important feature of PIOSCC is the presence of indistinct margins without a sclerotic outline. Our radiographs were in accordance with this statement. Ideally, PIOSCC should be entirely surrounded by the bone on radiographic examination, which could help in confirming an intraosseous origin. However, most tumors show extensive destruction of the jawbones and infiltration of the soft tissues at the time of diagnosis. In our patient, there was extensive destruction but no infiltration of overlying soft tissues. When discontinuity of the alveolar border of the tumor occurred, the diameter of the alveolar cortical perforation needed to be smaller than that of the underlying tumor, which may help in differentiating intraosseous carcinomas from tumors of the surface mucosa. ${ }^{8}$

Of the 36 cases of intraosseous SCC accepted by Eversole et al., 27 (75\%) appeared to originate in odontogenic cysts. ${ }^{9}$ In our patient also PIOC originated from KCOT. Treatment for PIOC is principally wide local resection, and radiotherapy and chemotherapy may be performed with adjunctive treatments. Local resection and reconstruction were done followed by radiotherapy in our patient. Its prognosis is relatively poor, and the 5 -year survival rate ranging from 30 to $40 \% .{ }^{10}$ Primary intraosseous carcinoma occasionally associates with the metastasis to the regional lymph nodes. No regional metastasis was observed at the initial examination of the present tumor. ${ }^{11}$ Our patient is on follow-up for 5 years and has not shown any signs of recurrence or metastasis to date.

\section{Conclusion}

Primary intraosseous carcinoma has no specific features and can be definitively diagnosed only upon fulfillment of various criteria after careful evaluation to rule out a distant primary tumor or invasion of a surface lesion or other odontogenic tumors. Knowledge of the clinical, radiographic, and histopathological features of PIOC allows accurate diagnosis and appropriate treatment of this rare malignancy. 


\section{References}

1. Grisar K, Schol M, Hauben E, et al. Primary intraosseous squamous cell carcinoma of the mandible arising from an infected odontogenic cyst: a case report and review of the literature. Oncol Lett 2016;12(6):53275331. DOI: 10.3892/ol.2016.5378.

2. Anneroth G, Hansen LS. Variations in keratinizing odontogenic cysts and tumors. Oral Surg Oral Med Oral Pathol 1982;54(5):530-546. DOI: 10.1016/0030-4220(82)90192-X.

3. Pindborg JJ, Kramer IR, Torloni $\mathrm{H}$ eds. Histological typing of odontogenic tumors, jaw cysts, and allied lesions. International Histological Classification of Tumors. Geneva, Switzerland: World Health Organization;1971.

4. To EHW, Brown JS, Ward-Booth RP, et al. Primary intraosseous carcinoma of the jaws. Three new cases and review of the literature. Br J Oral Maxillofac Surg 1991;29(1):19-25. DOI: 10.1016/02664356(91)90168-5.

5. Thomas G, Pandey M, Mathew A, et al. Primary intraosseous carcinoma of the jaw: pooled analysis of world literature and report of two new cases. Int J Oral Maxillofac Surg 2001;30(4):349-355. DOI: 10.1054/ijom.2001.0069.
6. Reichart PA, Philipsen HP, ed. Odontogenic Tumors and Allied Lesion. London: Quintessence Publishing Co. Ltd; 2004.

7. Huang JW, Luo HY, Li Q, et al. Primary intraosseous squamous cell carcinoma of the jaws. Archi Pathol Laborat Med 2009;133(11):18341840.

8. Kaffe I, Ardekian L, Peled M, et al. Radiological feature of primary intraosseous carcinoma of the jaws: analysis of the literature and report of a new case. Dentomaxillofac Radiol 1998;27(4):209-214. DOI: 10.1038/sj.dmfr.4600351.

9. Eversole LR, Sabes WR, Rovin S. Aggressive growth and neoplastic potential of odontogenic cysts. Cancer 1975;35(1):270282. DOI: 10.1002/1097-0142(197501)35:1<270::AID CNCR2820350134>3.0.CO;2-Y.

10. Cawson RA, Binnie WH, Speight PM, et al. Luca's pathology of tumors the oral tissues. London: Chur-chill Livingstone; 1998. pp. 36-76.

11. Suei $Y$, Tanimoto $K$, Taguchi A, et al. Primary intraosseous carcinoma: review of the literature and diagnostic criteria. J Oral Maxillofac Surg 1994;52(6):580-583. DOI: 10.1016/0278-2391(94) 90094-9. 